\title{
USING VIRTUAL REALITY AS A SUPPORT TOOL FOR THE OFFLINE ROBOT PROGRAMMING
}

\author{
Radovan HOLUBEK, Roman RUŽAROVSKÝ, \\ Daynier Rolando DELGADO SOBRINO
}

\author{
SLOVAK UNIVERSITY OF TECHNOLOGY IN BRATISLAVA, \\ FACULTY OF MATERIALS SCIENCE AND TECHNOLOGY IN TRNAVA, \\ INSTITUTE OF PRODUCTION TECHNOLOGIES,
} Ulica JÁna BotTu 2781/25, 91724 TRNAVA, Slovak REPUBliC

e-mail: radovan.holubek@stuba.sk,roman.ruzarovsky@stuba.sk,daynier_sobrino@stuba.sk Received: 30.05.2018, Accepted: 22.06.2018, Published: 19.09.2018

\begin{abstract}
The present article focuses on the possibilities of using Virtual Reality (VR) as a supporting tool by using the offline programming method for industrial robots. The philosophy of using such a process is hierarchically linked to the observance of methodological procedures for the proposal new workstations with using industrial robots. First, it is necessary to develop CAD models of the projected workplace, which can be imported into a suitable simulation environment for the creation of robotic simulations with support for visualization to the immersive VR environment. In our case, the CAD software Catia was used to develop a workstation, followed by integration of the CAD database into the simulation environment of Process Simulate (PS). Support for the visualization in the immersive environment of the Virtual Reality of Process Simulate was vested using the glasses headset HTC VIVE.
\end{abstract}

\section{Key words}

Offline robot programming (OLP), CAD models, Process Simulate software (PS), Virtual Reality (VR), headset HTC Vive

\section{INTRODUCTION}

The basis of each simulation, the appropriate simulation software selected, or the immersive view of the VR environment is the creation of a CAD model in a hierarchical sequence. Each created CAD model is based on 2D or 3D design. Its creation is dependent on several requirements in terms of shape, strength, etc. Creating an exact CAD model is one of the most important layout and design phases of each new workplace (1,2 and 3). Design features must also take into account the strength characteristics and requirements for the construction of the workstation. However, this article is focuses primarily on the creation of the simulation scenery of the ABB IRB120 industrial robot simulation scenery in software Process Simulate using the HTC Vive headset in the VR environment (4). 


\section{OBJECTIVES}

In order to use and validate the IRB 120 industrial robot guidance method using the function "Guide robot" with the HTC Vive's haptic hand controllers in the immersive virtual reality environment which support (PS), several necessary steps have to be taken (Fig.1):

1. Exact creation of the CAD model of the workstation,

2. Creating kinematics of the static CAD model of the robot IRB 120 and extending the library of this robot,

3. Defining a work tool (TCP, tool frame) in the PS software environment and extending the database of this tool,

4. Defining workobject and integrating into the PS library software database,

5. Define the control cabinet for the IRB 120 robot and integrate with the PS software library database.
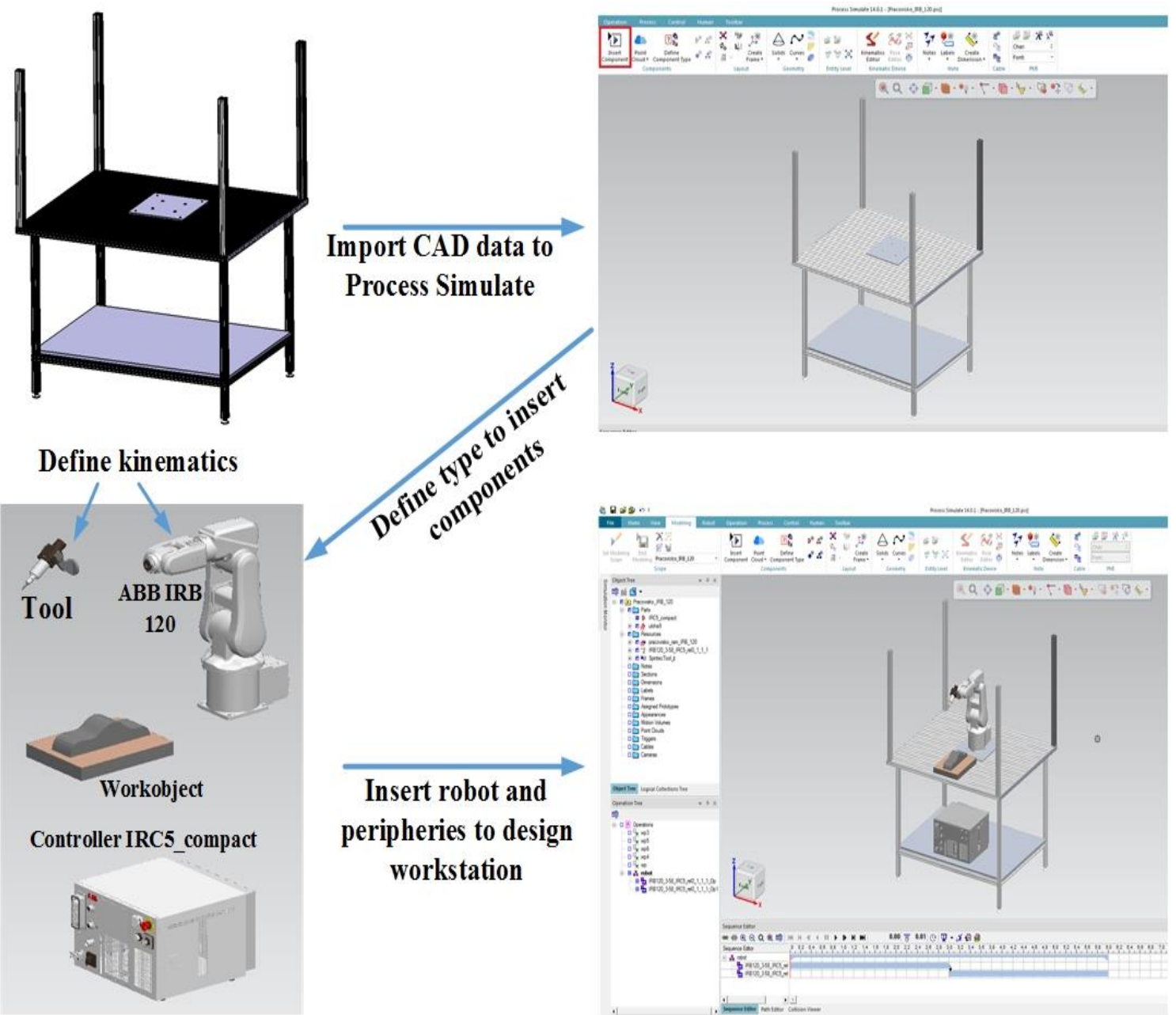

Fig. 1 Creation of layout workstation proposal using industrial robot IRB 120

Designing the kinematics of an IRB 120 industrial robot must be carried out in PS software, as industrial robot manufacturers usually only provide a static CAD model of robots without integrated kinematics (5). This intention of manufacturers can be explained by the fact that industrial robot manufacturers prefer using their programming software for OLP programming where this kinematics is located. In this case, Robotstudio from ABB was not selected for the development of the OLP program, where RobotStudio also comprises integrated kinematics, and therefore OLP programming support, but instead in the Process Simulate software, which also enables OLP robot programming by a lot of variety of industrial robot producers $(6,7$ and 
8). ABB's industrial robot IRB 120 was chosen based on the fact that this industrial robot as well as the real workplace are built at our Institute. The kinematics of the industrial robot IRB 120 and its limits on individual axes are shown in Fig. 2. In order to create kinematics, it is necessary to define the robot:

- Base frame that was defined in the robot base,

- Serial connection of individual kinematic nodes of each axes,

- Tool center point (TCP), the point where the tool mount to robot (in this case 6. robot axes)

- Rotation limits of each robot axis within the min-max range.

For the selected tool, it was necessary to define the base frame and the tool center point of the TCP tool (which is the exact point to be connected with the end axis of the robot).

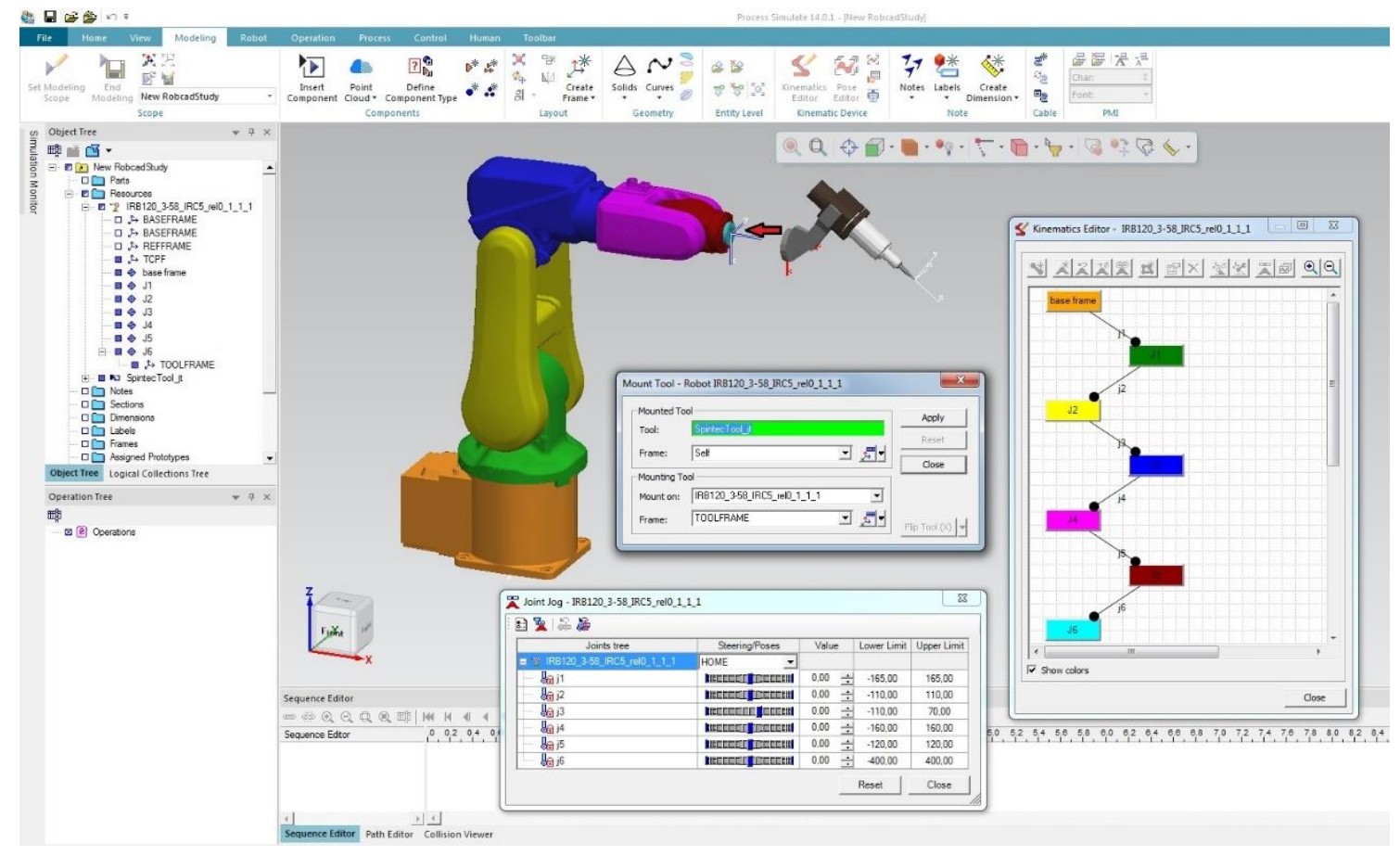

Fig. 2 Creating kinematics of the IRB 120 robot, and using the function "mount tool" for the connection to the robot

\section{METHODS}

Process Simulate VR is easy to use and enables simple and intuitive interaction with other workers. As the loaded data is connected to Process Simulate, the changes in the VR environment automatically update the data in the study. Wearing the VR headset and using the haptic hand controllers, you can teleport yourself around the space, highlight objects, measure, add markups, illuminate dark areas with a flashlight, play simulations and even move objects and jog robots. The VR window in Process Simulate lets users not wearing a VR headset watch a 2D monitor to see the same view as the person that is immersed, so that both of them can communicate and collaborate (9).

The based on the workstation layout purpose with the integration of industrial robot and worktool and other peripherals (CAD proposal of the workstation, controller IRC 5, workobject) in the PS software environment, it was possible to start exploring the possibility of using the robot working tool to the required workobject points in the immersive VR/PS environment. First, it was necessary to load the created layout of the workstation into the 
immersive VR environment. Support for visualization of creative workstation layouts and simulations in the VR environment provides new possibilities in the PS software (the first support was released on 01/2018). Fig. 3 shows the process of loading the workplace with the robot into the VR environment and then displaying the workspace in the VR by supporting the HTC Vive headset. PS software supports only for HTC Vive headset.

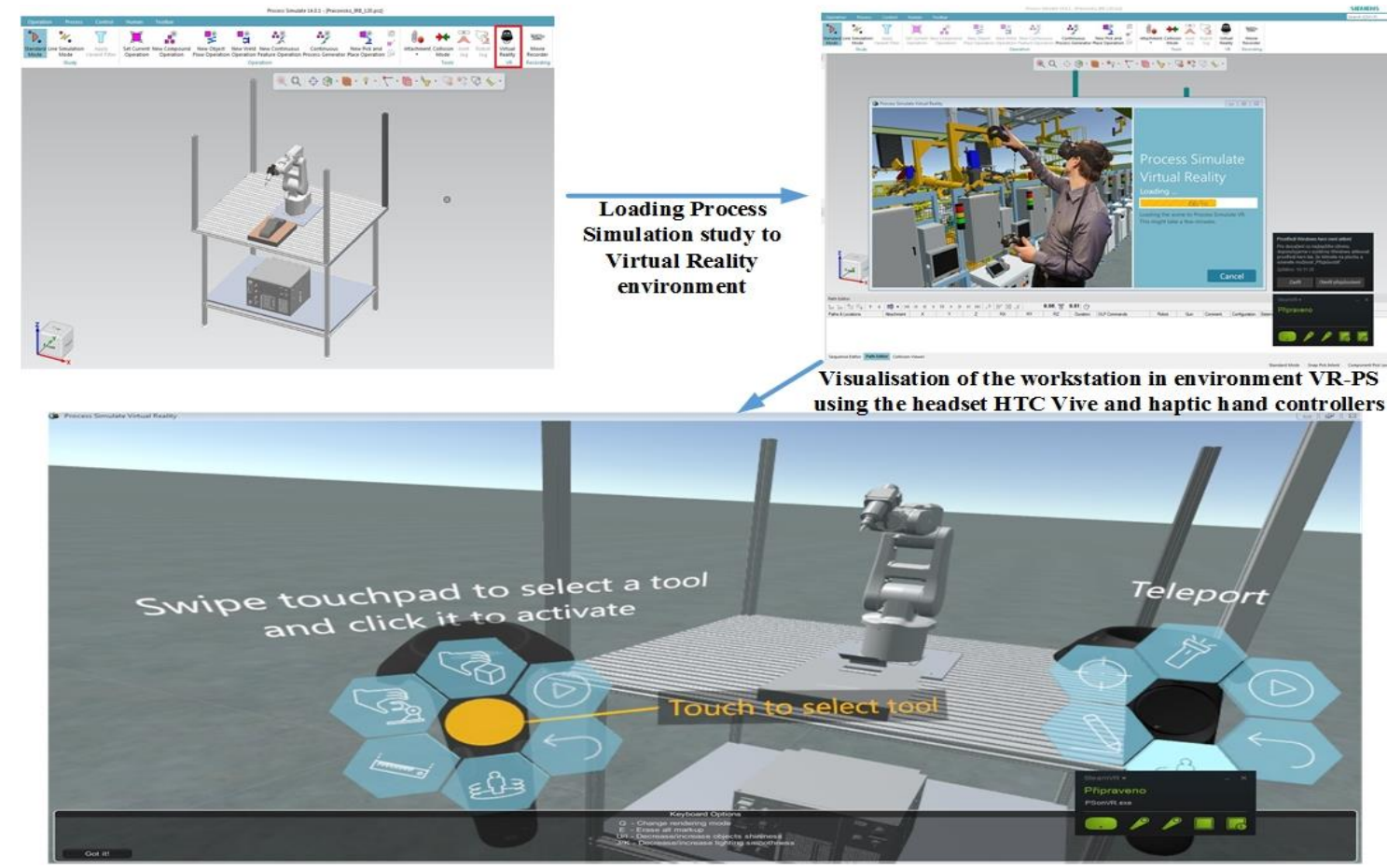

Fig. 3 Connection of Process Simulate to Virtual Reality environment

\section{RESULTS}

The aim of viewing a created workspace in the immersive VR environment is to use of the multiple support function of the HTC Vive haptic hand controllers. In our research, an objective was using the "Guide Robot" on the basis of which it is possible to move through the gripping of the tool to the desired or target on workobject. A very important factor in the VR environment is that the robot's movement using the haptic hands controllers via the "Guide Robot" function is an instant interaction connecting also into the PS workstation (Fig. 4).

Based on the correct positioning of the robot to the work object, it is possible to create a target or create an exact position in the POSE Editor - PS. After creating the correct positions in Pose Editor, it is possible to perform a Robot device operation between these two positions to create a robotic simulation (Path) on the surface of work object $(10,11)$. Validation of the positions created looks very simple as it is created with only two points but in the research it is mainly the verification of the possibility of using virtual reality for this way of programming and creation of the trajectories of industrial robots. This approach is based on innovation and interaction of multiple environments, with the possibility of linking the generated program to the robot in interaction with the real existing workstation. This connectivity is enhanced by the use of industrial robot programming using offline methods to further guide an industrial robot to the desired position through the Virtual reality - software PS module shown in Fig. 5. 


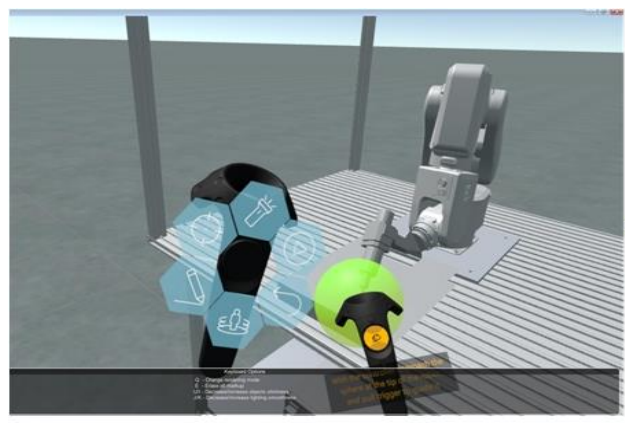

Robot Jog to Pose1

Robot Jog to Pose2

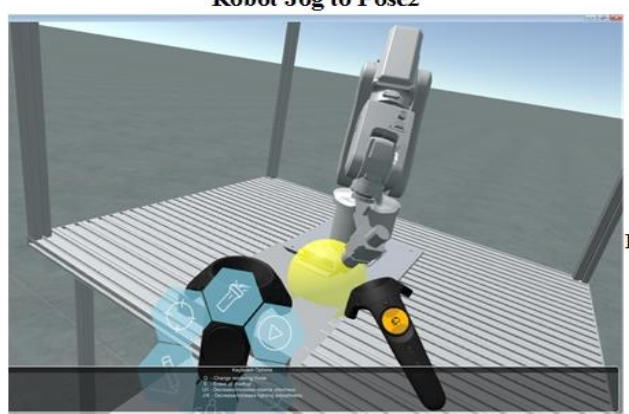

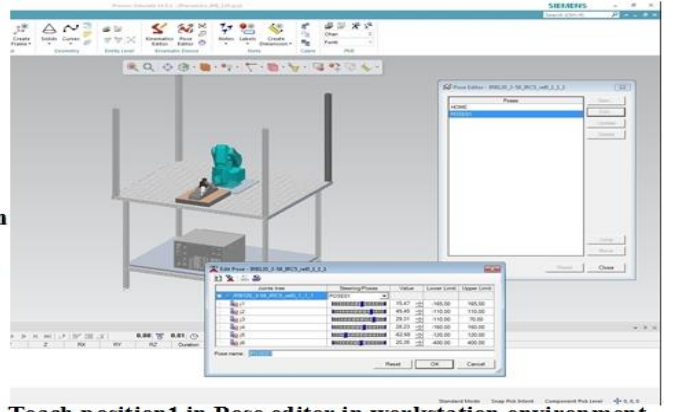

Teach position1 in Pose editor in workstation environment

Teach position 2 in Pose editor in workstation environment

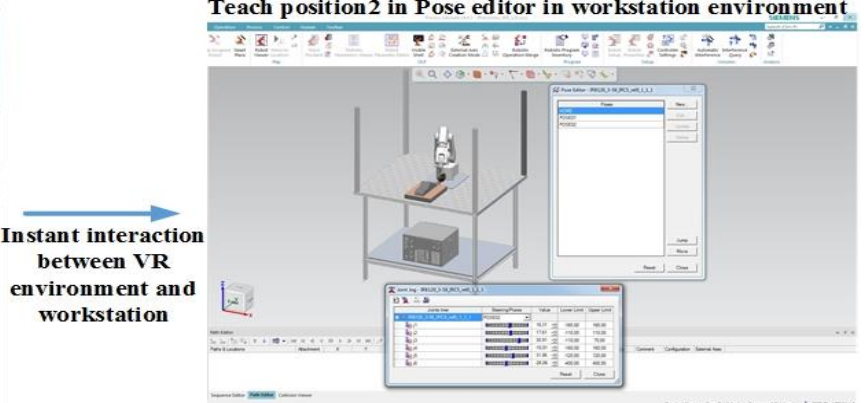

Fig. 4 Instant interaction between Process Simulate and Virtual Reality environment
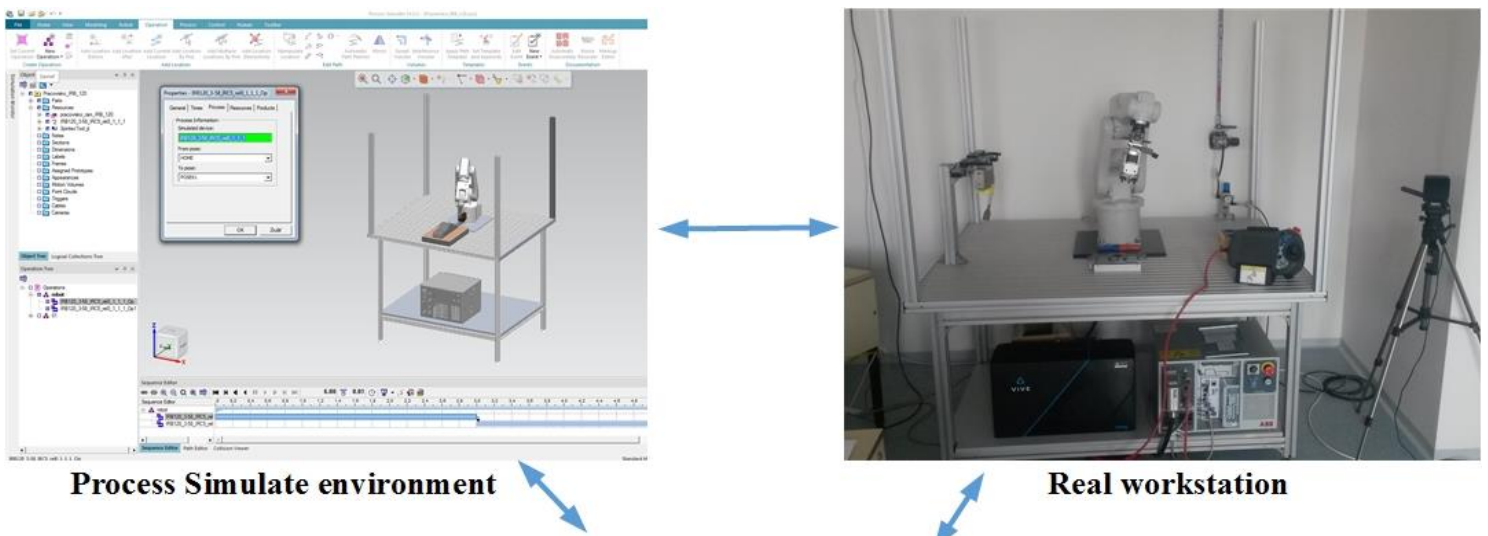

Real workstation

Virtual Reality environment

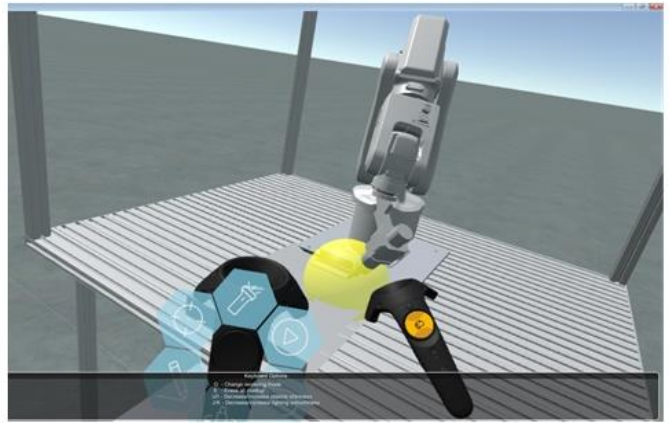

Fig. 5 Possibilities of connecting PS environment, VR environment and a real workstation

\section{CONCLUSION AND FUTURE RESEARCH}

The use of VR support in manufacturing systems and especially in robotics is a rapidly growing area. The main aim of supporting the VR in the design of various workstations using production devices, systems and industrial robots is the most realistic visualization even in the 
design phase, without the need to have realistic production systems, robot etc. Numerous CAD and simulation software manufacturers have responded to this demand for visualization of designs just in the immersive VR environment that is most often viewed via the VR glass headset. This is the VR view method, which is the most affordable in terms of initial financial investment. Most manufacturers have these VR headset supplemented by hand controllers (HTC Vive, Oculus Rift etc.) with monitoring the user's movement in space area. VR support in production devices and robotics enables most of the functions like Jogging Robot, measuring objects, teleport of the entire study or particular part, the ability to grab the CAD model, thus perfect viewing of invisible parts of machines and equipment, possibilities of the debugging collisions state, guiding the robot with a gripper or work tool to the desired position, simulation tracking etc. The aim of this article was to try to use the robot to use the selected work object targets and to teach the robot individual positions in the PS software programming environment. This area of research into the use of the VR in manufacturing systems and robotics is an interesting and desirable subject for the future, which is addressed by several research institutions as well as the industrial sector.

\section{Acknowledgement}

This paper was supported by the KEGA-021STU-4/2018 Project of Development of a laboratory for the design and maintenance of production systems supported by the use of Virtual Reality. This support is gratefully acknowledged.

\section{References:}

1. TAHRIRI, F., MOUSAVI, M., YAP, H.J., ZAWIAH, M.D.S., TAHA, Z. 2015. Optimizing the robot arm movement time using virtual reality robotic teaching system. International Journal of Simulation Modelling, 14(1). pp. 28-38. ISSN 1726-4529.

2. T.S. MUJBER, T. SZECSI, M.S.J. HASHMI. 2004. Virtual reality applications in manufacturing process simulation. Journal of Materials Processing Technology, pp. 155-156, 1834-1838.

3. VELÍŠEK, K., HOLUBEK, R., DELGADO SOBRINO., D. R., RUŽAROVSKÝ, R., VETRÍKOVÁ, N. 2016. Design of a robotized workstation making use of the integration of CAD models and robotic simulation software as way of pairing and comparing real and virtual environments. Computing and Solutions in Manufacturing Engineering, Vol. I. Brasov, Romania. Transilvania University of Brasov, pp. 49- 50, 2016.

4. ADJALI, O., HINA, M.D., DOURLENS, S., RAMDANE-CHERIF, A. 2015. Multimodal Fusion, Fission and Virtual Reality Simulation for an Ambient Robotic Intelligence. International Conference on Ambient Systems Networks and Technologies, 52, pp. 218-225.

5. GUERRERO, L.V., LÓPEZ, V.V. \& MEJÍA, J.E. 2014. Virtual Commissioning with Process Simulation (Tecnomatix), Computer-Aided Design and Applications, pp. S11-S19.

6. Neto P (2013) Off-line programming and simulation from CAD drawings: robot-assisted sheet metal bending. Industrial Electronics Society, IECON 2013-39th Annual Conference of the IEEE 20:4235-4240.

7. TURNER, C. J., HUTABARAT, W., OYEKAN, J. 2016. Discrete Event Simulation and Virtual Reality Use in Industry: New Opportunities and Future Trends IEEE Transactions on HumanMachine Systems, 46 882-894.

8. LORENZ M., SPRANGER M., RIEDEL T., PÜRZEL F., WITTSTOCK V., KLIMANT, P. 2016. CAD to VR - a methodology for the automated conversion of kinematic CAD models to virtual reality. Research and Innovation in Manufacturing: Proceedings of the 48th CIRP Conference on Manufacturing Systems, Vol. 41, pp. 358-363.

9. Plm Automation Siemens [on-line]: https://community.plm.automation.siemens.com/t5/Tecnomatix-News/Tecnomatix-14-What-sNew/ba-p/462477\#vr 
10. HOLUBEK, R., DELGADO SOBRINO, D.R., KOŠŤÁL, P., RUŽAROVSKÝ, R., VELÍŠEK, K. 2017. Using Virtual Reality tools to support simulations of manufacturing instances in Process Simulate: The case of an iCIM 3000 system. MATEC Web of Conferences. 137.

11. HOLUBEK, R., RUŽAROVSKÝ, R., DELGADO SOBRINO, D.R., KOŠŤÁL, P., ŠVORC, A., VELÍŠEK, K. 2017. Novel trends in the assembly process as the results of human - the industrial robot collaboration. MATEC Web of Conferences. 137.

\section{ORCID:}

Radovan Holubek

0000-0003-0844-8603

Roman Ružarovský

$0000-0002-9465-4544$

Daynier Rolando Delgado Sobrino 0000-0001-9253-6141 